\title{
EFFECT OF CUMULUS CELLS ON CANINE OOCYTE VITRIFICATION USING DAP213 CRYOTOP METHOD
}

\author{
M.A. ABDEL-GHANI ${ }^{*}$ A. and H. SUZUKI** \\ * Department of Theriogenology, Faculty of Veterinary Medicine, Assiut University, Assiut, Egypt. \\ Assiut, 71526, Egypt, Phone/Fax: 2-088-2334699// 2-088-2-366503; e-mail: mohammed ali76@hotmail.com \\ ** Research Unit for Functional Genomics, National Research Center for Protozoan Diseases, Obihiro University of \\ Agriculture and Veterinary Medicine, Inada, Obihiro, 080-8555, Japan.
}

Received at: $13 / 5 / 2014$

Accepted: 24/6/2014

\section{ABSTRACT}

The present study investigated the influence of cumulus cells on vitrification of canine germinal vesicle stage oocytes, and assessed the ability of vitrified -warmed oocytes for further maturation in vitro. Selected cumulus-oocyte complexes (COCs) or cumulus-free oocytes or partially denuded were vitrified in DAP 213 solution. The vitrified-warmed oocytes were observed morphologically, and the plasma integrity was assessed. The viable oocytes in each group were cultured in TCM-199 for $72 \mathrm{~h}$ at $38.5{ }^{\circ} \mathrm{C}$ in $5 \% \mathrm{CO} 2,5 \% \mathrm{O} 2$ and $90 \% \mathrm{~N} 2$. All media were supplemented with $10 \%$ of FCS, $50 \mathrm{ng} / \mathrm{mL}$ of EGF, $2 \mu \mathrm{g} / \mathrm{mL}$ of estradiol $-17 \beta, 0.1 \mathrm{IU} / \mathrm{mL}$ of $\mathrm{hCG}$, $0.1 \mathrm{IU} / \mathrm{mL}$ of FSH, $0.25 \mathrm{mM}$ of pyruvic acid, $100 \mu \mathrm{M}$ of $\beta$-mercaptoethanol, and antibiotics. The viability of vitrified-warmed intact oocytes $(52.8 \%)$ was higher than denuded oocytes $(33.9 \%, \mathrm{P}<0.05)$, however, there is no differences between the partially denuded oocytes $(43.9 \%)$ and denuded oocytes $(33.9 \%, \mathrm{P}>0.05)$. The highest percentage of M-II oocytes $(\mathrm{P}<0.05)$ was observed in the intact group $(3.1 \%)$ compared to the denuded group $(0.8 \%)$. When compared to the denuded group $(2.3 \%)$, an increase $(\mathrm{P}<0.05)$ in the proportions of $\mathrm{M}-\mathrm{I}$ oocytes was observed in the intact group $(8.3 \%)$ and partially denuded group $(5.5 \%)$. The overall meiotic resumption was greater $(\mathrm{P}<0.05)$ in the intact and partially denuded groups than in denuded group. In conclusion, the contact of cumulus cells with canine oocytes improved the viability after vitrification and enhanced the meiotic resumption of oocytes after in vitro maturation.

Key words: Canine, cryotop, cumulus-oocyte complexes, vitrification

\section{INTRODUCTION}

The potential benefits of assisted reproductive techniques (ARTs) including in vitro maturation (IVM), in vitro fertilization (IVF), and oocyte and embryo vitrification in canine species are connected to the protection of species that exposed to extinction, increase the efficiency of animal breeding, preserve valuable genetically animals and use germ cells effectively (Songsasen et al., 2003). In the last years, the biotechnologies applied to reproduction have been greatly improved both in human and domestic species. However, the particular characteristics of inherent physiological uniqueness of the gamete physiology have complicated the adaptation of biotechnological knowledge compared to other species (Abdel-Ghani et al., 2012; Bolamba et al., 2006 and Concannon et al., 1989).

The oocyte cryopreservation and maturation in vitro are established protocols that are commonly used in IVF centers and present an ideal option for women with cancer to retain child-bearing potential before chemotherapy or radiotherapy as well as provide a good option for women who want, for various social reasons, to delay pregnancy but still retain their fertility (Van den Broecke et al., 2001). Regarding the dogs, there are many countries that suffer from acute shortage of guide dogs for the blind. One of the most contributing features of the lack of guide dogs seems to be the castration of both female and males in advance of the beginning of training (Ishijima et al., 2006). That, once the newly trained dogs were to 
distinguish themselves as superior guide dogs, unfortunately, they could never produce offspring, which may be especially fit for such training. Moreover, the removed reproductive organs were treated as waste materials. Ordinarily, both of males and females used for breeding are not evaluated for their potential to serve as guide dogs (Abe et al., 2008; Ishijima et al., 2006 and Suzuki et al., 2008). This current situation urgently requires countermeasures to meet and sustain the supply of high quality guide dogs. These countermeasures should include a novel breeding system; hence, the oocyte vitrification and further stimulation represent a potential means for female germplasm conservation. This aspect reinforces the need to perform experiments committed to optimize the oocyte vitrification results, and subsequently to assure an adequate number of oocytes destined for IVM.

Moreover, the successful cryopreservation of oocytes depends on the tolerance of the oocytes to cryoinjury during the vitrification and warming procedures. One of the most serious problems for successful vitrifiaction of canine oocytes seems to be the large amount of lipid content within the canine oocytes cytoplasm (Abe et al., 2011). Similarly, bovine and porcine oocytes have lipid particles (Fujihira et al., 2004). However, the density of the lipid is much higher in canine oocytes (Abe et al.,2011) and as a consequence of this inability to develop a consistently effective vitrification system, other techniques such as IVF and IVC that require in vitro oocyte culture have also met with limited success (England et al., 2001).

Therefore, the objective of this study is to investigate the influence of cumulus cells on vitrification of canine germinal vesicle $(\mathrm{GV})$ stage oocytes in DAP 213 solution. In this regard, first, the oocytes were vitrified. Second, the vitrified-warmed oocytes were in vitro matured for further improving the cryopreservation method for canine oocytes and embryos.

\section{MATERIALS and METHODS}

\section{A)- Experiment I: \\ 1- Collection and preparation of canine cumulus- oocyte complexes (COCs):}

Ovaries were collected from healthy domestic bitches undergoing routine ovariohysterectomy in local veterinary clinics. The animals $(n=15)$ were of various breeds and 5 months to 6 years of age. Both ovaries from each bitch were transported to the laboratory within $1 \mathrm{~h}$ in a thermo flask containing physiological sterile saline at $37{ }^{\circ} \mathrm{C}$. After transportation, the fat, ligaments, and medulla were carefully trimmed off and removed. The COCs were released by repeatedly slicing the ovarian cortex with a scalpel blade (21BZ0082, Feather, Osaka, Japan) at $37^{\circ} \mathrm{C}$. These COCs were placed in $35 \mathrm{~mm}$ petri dish (3001, Falcon, Becton Dickinson, Lincoln Park, NY, USA) containing modified phosphate buffered saline medium (PB1) (Whitingham 1974) supplemented with $3 \mathrm{mg} / \mathrm{mL}$ of bovine serum albumin (BSA; A6003, Sigma, St. Louis, MO, USA), $100 \mathrm{IU} / \mathrm{mL}$ of penicillin (B40076, Calbiochem, Inc., La Jolla, CA, U.S.A) and $100 \mu \mathrm{g} / \mathrm{mL}$ of streptomycin (SSD702, MEIJI Co., Tokyo, Japan), then examined under a dissecting microscope (SMZ1500, Nikon Instech Co., Ltd. Tokyo, Japan). After three washes in the same medium, the COCs were selected according to previously described criteria (De los Reyes et al., 2005) under an inverted microscope (DMIR/E, LEICA Co., Wetzlar, Germany). Namely, the parameters were those reported to favor meiotic competence based on the uniformity of ooplasm, homogeneous dark cytoplasm with more than three layers of compact cumulus cells and oocytes $>110$ $\mu \mathrm{m}$ in diameter. The vitelline diameter of COCs was measured with a calibrated ocular micrometer.

\section{2- Removal of cumulus cells:}

The oocytes were partially or completely denuded by exposure to $0.1 \%$ of hyaluronidase (H3506, Sigma) in PB1 for 10 min with gentle pipetting using a finebore pipette, by repeated aspiration and expulsion.

\section{3- Vitrification of oocytes and warming:}

The vitrification protocol used was as previously described by Abe et al. (2010). Briefly, the oocytes, after rinsing in human tubal fluid medium (HTF), was transferred into $35 \mathrm{~mm}$ petri dish containing cryoprotectant (1 M Dimethyl sulfoxide, MSO; Sigma) at room temperature (RT), which was then placed in ice water for $5 \mathrm{~min}$ to allow DMSO to thoroughly pass the oocytes (Newton et al., 1998). Subsequently, prepared oocytes exposed to DAP213 solution (2 M DMSO; $1 \mathrm{M}$ acetamide, Sigma; $3 \mathrm{M}$ propylene glycol, Wako), maintained at $0^{\circ} \mathrm{C}$ where the petri dish was kept in ice water for $5 \mathrm{~min}$ before being placed on a cryotop sheet (Kit-azato Supplies, Tokyo, Japan). Immediately, the cryotop plunged into liquid nitrogen for storage until use. For warming, the cryotop holder containing oocytes was transferred from liquid into $\mathrm{PB} 1$ medium $\left(37^{\circ} \mathrm{C}\right)$ containing 0.25 $\mathrm{M}$ sucrose. Then, the recovered oocytes were transferred to PB1 medium containing $3 \mathrm{mg} / \mathrm{mL}$ BSA and washed 5 times.

\section{4- Evaluation of plasma membrane integrity:}

Immediately after warming and the removal of the cryoprotectant, the vitrified warmed oocytes were observed morphologically under inverted microscope. The oocytes were assigned into four groups; Group 1 (fresh), Group 2 (Vitrified-intact oocytes), Group 3 (Vitrified-partially denuded oocytes), and Group 4 (Vitrified-completely denuded oocytes). The 
completely denuded oocytes, partially denuded oocytes and intact oocytes were stained with 10 $\mu \mathrm{g} / \mathrm{mL}$ of propidium iodide (PI; P4864, Sigma) in PB1 containing $0.1 \%$ of polyvinyl alcohol (P8136, Sigma) and incubated for $15 \mathrm{~min}$ in darkness. Afterwards, they were washed three times in PB1, placed on glass slides, and overlaid with a coverslip. The oocytes were examined under a fluorescence microscope with UV light (Nikon, Tokyo, Japan) and the plasma membrane integrity of the oocytes was assessed.

\section{B)- Experiment II:}

1. In vitro maturation of vitrified-warmed oocytes: The oocytes in each group were cultured in TCM-199 (Earle's salt $+2.2 \mathrm{~g} / \mathrm{L}$ sodium bicarbonate, buffered with 25 mMHepes; Gibco-Invitrogen Life Technologies, NY, USA) supplemented with $10 \%$ of fetal calf serum (FCS), $50 \mathrm{ng} / \mathrm{mL}$ of epidermal growth factor (EGF) (Sigma), $2 \mu \mathrm{g} / \mathrm{mL}$ of estradiol$17 \beta$ (Sigma), $0.1 \mathrm{IU} / \mathrm{mL}$ of human chorionic gonadotrophin (hCG) (Sankyo, Tokyo, Japan), 0.1 $\mathrm{IU} / \mathrm{mL}$ of follicular stimulating hormone (FSH) (Sigma), $0.25 \mathrm{mM}$ of pyruvic acid (Wako, Ltd. Tokyo, Japan), $100 \mu \mathrm{M}$ of $\beta$-mercaptoethanol (Sigma), $100 \mathrm{IU} / \mathrm{mL}$ of penicillin and $100 \mu \mathrm{g} / \mathrm{mL}$ of streptomycin.

In all experimental groups, 10 oocytes were incubated in $100 \mu \mathrm{L}$ of each medium in $35 \mathrm{~mm}$ petri dish covered with mineral oil (NacalaiTesque, Inc. Kyoto, Japan) at $38.5{ }^{\circ} \mathrm{C}$ in a humidified atmosphere of $5 \%$ $\mathrm{CO} 2,5 \% \mathrm{O} 2$, and $90 \% \mathrm{~N} 2$ for $72 \mathrm{~h}$.

\section{Assessment of nuclear status:}

Cumulus cells of oocytes were removed by exposure to $0.2 \%$ of hyaluronidase for $15 \mathrm{~min}$ with gentle pipetting. The denuded oocytes were fixed and permeabilized in phosphate buffer saline (PBS) containing 3.7\% (w/v) of paraformaldehyde (WAKO) for $15 \mathrm{~min}$. Then, they were washed three times in PB1 supplemented with $3 \mathrm{mg} / \mathrm{mL}$ of BSA. The cumulus-free oocytes were stained with $10 \mu \mathrm{g} / \mathrm{mL}$ of propidium iodide (PI) in PBS containing $0.1 \%$ of polyvinyl alcohol and incubated for $15 \mathrm{~min}$ in darkness. Afterwards, they were washed three times in PB1, placed on glass slides, and overlaid with a coverslip. The chromatin state was evaluated under a fluorescence microscope with UV light to determine the meiotic stage according to the study De los Reyes et al. (2005): (a) immature or germinal vesicle (GV, Fig. 2-A), when the nucleolus was surrounded by condensed chromatin; (b) resumption of meiosis or germinal vesicle break down (GVBD, Fig. 2-B), when the chromatin was dispersed; (c) metaphase I (M-I, Fig. 2-C), when chromosomes were highly compact in a metaphasic plate and migrating to the poles; (d) metaphase II; (M-II, Fig. 2-D), when chromosomes were in second metaphase with extrusion of the first polar body; (e) degenerated (deg, Fig. 2-E), when oocytes displayed loss of membrane integrity or dispersed chromosomes; (f) oocytes with unidentifiable chromatin were counted as unclassified (Fig. 2-F).

\section{C) - Statistical analysis:}

Oocytes were randomly allocated to experimental groups. The survival ratios of oocytes were performed by Kruskal-Wallis ANOVA on Ranks followed by Dunn's multiple comparisons. Statistics were calculated with the help of JMP v5.0.1 (SAS campus drive, Cary, NC, USA).

The proportion of oocytes reaching each stage of nuclear maturation in each treatment group were subjected to arcsine transformation, and evaluated by ANOVA (Statistical Analysis System, SPSS, USA), followed by post HOC multiple comparisons using the least significant difference (LSD) test. The results were expressed as mean \pm standard deviations. All differences were considered significant at a confidence level of $\mathrm{P}<0.05$.

All experiments were carried out in accordance with the guidelines for the care and use of the animals approved by Obihiro University of Agriculture and Veterinary Medicine, Japan.

\section{RESULTS}

\section{A)- Experiment I (oocyte vitrification):}

As shown in Table 1, the recovery rates of oocytes were in a range of 95 to $98.1 \%$. The majority of vitrified-warmed oocytes in each group were morphologically intact, although some of the vitrified-warmed oocytes exhibited partly disrupted cytoplasm. There was no difference between the vitrified groups morphologically (intact; 88.7\%, partially denuded and $80.7 \%$, completely denuded; $78.6 \%)(\mathrm{P}>0.05)$, although it was higher in vitrifiedwarmed intact oocytes compared to other groups $(\mathrm{P}>$ $0.05)$.

The viability of vitrified-warmed intact oocytes assessed by PI staining (52.8\%) was higher than vitrified-warmed denuded oocytes $(33.9 \%, \mathrm{P}<0.05)$, however, there is no differences between the vitrifiedwarmed partially denuded oocytes $(43.9 \%)$ and vitrified-warmed denuded oocytes $(33.9 \%, \mathrm{P}>0.05)$.

\section{B)- Experiment II (in vitro maturation of vitrified- warmed oocytes):}

The highest percentage of M-II oocytes $(\mathrm{P}<0.05)$ was observed in the intact group $(3.1 .0 \%)$ compared to the denuded group $(0.8 \%)$ (Table 2$)$. When compared to the denuded group $(2.3 \%)$, an increase 
$(\mathrm{P}<0.05)$ in the proportions of M-I oocytes was observed in the intact group $(8.3 \%)$ and partially denuded group $(5.5 \%)$.

The proportion of GV oocytes in the intact group was similar $(\mathrm{P}>0.05)$ to the value for oocytes in denuded group and lower $(\mathrm{P}<0.05)$ than that for oocytes in the partially denuded group. The overall meiotic resumption was greater $(\mathrm{P}<0.05)$ in the intact and partially denuded groups than in denuded group.

Table 1: Percentages of normal morphologically and plasma integrity of oocytes after vitrification using DAP213 cryotop method.

\begin{tabular}{|c|c|c|c|c|}
\hline \multirow[b]{2}{*}{ Parameters } & \multirow[b]{2}{*}{ Fresh } & \multicolumn{3}{|c|}{ Vitrified } \\
\hline & & Intact & $\begin{array}{l}\text { Partially } \\
\text { denuded }\end{array}$ & $\begin{array}{c}\text { Completely } \\
\text { denuded }\end{array}$ \\
\hline No. of vitrified oocytes & - & 108 & 120 & 116 \\
\hline No. of oocytes examined (\%) & 110 & $106(98.1)$ & $\begin{array}{l}114 \\
(95)\end{array}$ & $\begin{array}{c}112 \\
(96.6)\end{array}$ \\
\hline $\begin{array}{c}\text { No. of oocytes with normal morphology } \\
\text { (\% of examined) }\end{array}$ & $\begin{array}{c}110 \\
(100 \%)^{\mathrm{a}}\end{array}$ & $94(88.7)^{\mathrm{ab}}$ & $\begin{array}{c}92 \\
(80.7)^{\mathrm{b}}\end{array}$ & $\begin{array}{c}88 \\
(78.6)^{\mathrm{b}}\end{array}$ \\
\hline $\begin{array}{l}\text { No. of oocytes with normal plasma integrity } \\
\text { (\% of examined) }\end{array}$ & $\begin{array}{c}108 \\
(98.1)^{\mathrm{a}}\end{array}$ & $56(52.8)^{\mathrm{b}}$ & $\begin{array}{c}50 \\
(43.9)^{\mathrm{bc}}\end{array}$ & $\begin{array}{c}38 \\
(33.9)^{\mathrm{c}}\end{array}$ \\
\hline
\end{tabular}

Values with different superscripts were different $(\mathrm{P}<0.05)$ in the same row in each treatment.

Table 2: Nuclear status ofcanine oocytesafter $72 \mathrm{~h}$ in vitro culture in TCM-199.

\begin{tabular}{|c|c|c|c|c|c|c|c|c|}
\hline \multirow[t]{2}{*}{ Group } & \multirow{2}{*}{$\begin{array}{c}\text { No. of } \\
\text { oocytes } \\
\text { Examined }\end{array}$} & & & & & & & \\
\hline & & GV & GVBD & MI & MII & Deg. & unclassified & GVBD-MII \\
\hline Intact & 56 & $22.8 \pm 0.2^{\mathrm{a}}$ & $7.1 \pm 0.2^{\mathrm{a}}$ & $8.3 \pm 0.6^{\mathrm{a}}$ & $3.1 \pm 1.0^{\mathrm{a}}$ & $31.2 \pm 0.6^{\mathrm{a}}$ & $25.5 \pm 0.2^{\mathrm{a}}$ & $20.0 \pm 0.6^{\mathrm{a}}$ \\
\hline Partially & 50 & $26.7 \pm 0.1^{\mathrm{a}}$ & $12.0 \pm 0.9^{b}$ & $5.5 \pm 2.0^{\mathrm{a}}$ & $3.2 \pm 1.1^{\mathrm{a}}$ & $25.6 \pm 1.8^{\mathrm{a}}$ & $28.8 \pm 0.9^{\mathrm{a}}$ & $22.3 \pm 2.7^{\mathrm{a}}$ \\
\hline Denuded & 38 & $32.2 \pm 0.7^{\mathrm{a}}$ & $10.2 \pm 1.5^{\mathrm{ab}}$ & $2.3 \pm 0.2^{\mathrm{b}}$ & $0.8 \pm 2.4^{\mathrm{b}}$ & $35.9 \pm 1.5^{\mathrm{a}}$ & $20.6 \pm 0.5^{b}$ & $13.7 \pm 1.1^{\mathrm{b}}$ \\
\hline
\end{tabular}

GV, germinal vesicle; GVBD:germinal vesicle break down; MI: metaphase I; MII: metaphase II.

Values with different superscripts were different $(P<0.05)$ in the same column. 


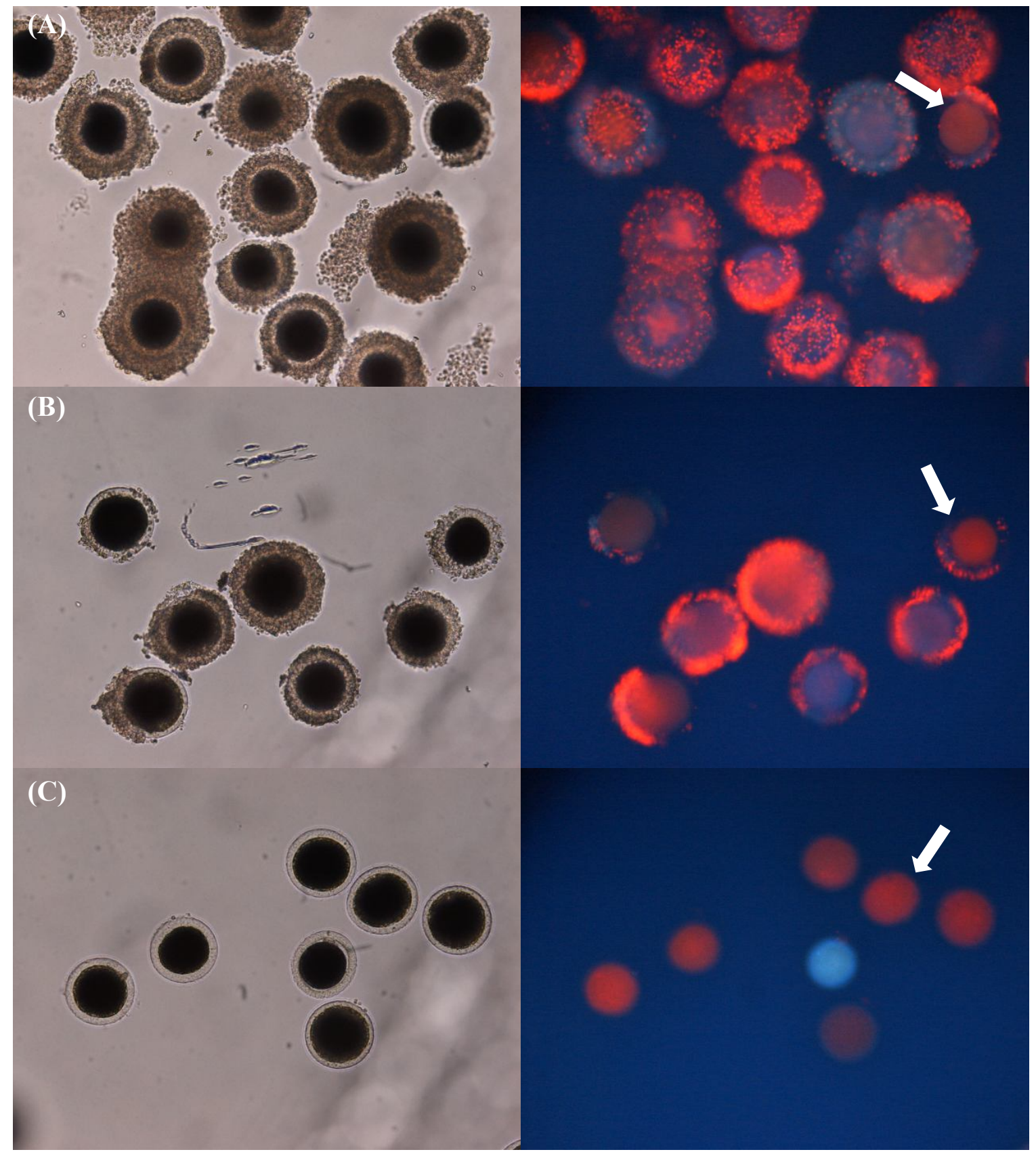

Fig. 1: Morphological appearance of canine oocytes after vitrification by the DAP-cryotop method under: light microscope (normal, left side) or UV fluorescence microscope (Right side).Propidium iodide (PI) staining revealed that the oocytes stained red were damaged (arrows). (A) Intact oocytes; (B) Partially denuded; (C) Completely denuded $(\times 100)$. 
(A)

(B)

(C)

(D)

(E)

(F)

Fig. 2: Fluorescence photomicrographs of canine oocytes stained with propidium iodide showing chromatin configuration. (A) Germinal vesicle: condensed chromatin (arrow); (B) Germinal vesicle break down: chromatin was dispersed (arrow); (C) Metaphase I: chromosomes were compact in a metaphasic plate and migrating to the poles (arrow); (D) Metaphase II: the extrusion of the first polar body (arrow); (E) Degenerated: dispersed chromosomes (arrow); (F) Unclassified: unidentifiable chromatin $(\times 400)$. 


\section{DISCUSSION}

Abe et al. (2011) reported that canine oocytes could be preserved by vitrification using DAP213. However, the viability of plasma membrane integrity of the vitrified oocytes as assessed by PI staining in the DAP213 method was low. Since the cumulus cells are found in vivo within developing follicle, and undoubtedly play an important role in the oocyte nutrition and protection, the present study was designed to investigate the effect of the cumulus cells on the vitrification of canine germinal vesicle (GV) stage in DAP213 solution. In addition, the ability of vitrified -warmed oocytes for further maturation in vitro was investigated.

As shown in Table 1, the vitrification of intact oocytes in DAP213 solution with cryotop sheet was much more effective than the vitrification of partially denuded and complete denuded for the preservation of canine GV stage oocytes. On the other, the results have showed that the rate of meiotic resumption in cumulus-enclosed oocytes was significantly higher than that of cumulus-denuded oocytes.

The role of cumulus cells in canine species may be more important than in other animals (Luvoni et al., 2001), because the multilayered cumulus cell mass remains closely attached around oocyte up to the morula stage (Renton et al., 1991). The potential role of cumulus cells has been the subject of several reviews, all of which suggested that these cells were intimately connected with the oocyte through long microvilli that traverse through the zona to contact the oolemma, so as to form gap junctions and desmosomes (Motta et al., 1994); one of the routes by which the cumulus cells transmit factors to the oocyte is gap junctional communication (GJC) (Gilula and Beers, 1978). Thus, the GJC between cumulus cells and the oocytes plays an important role in the transmission of meiosis-activating components and some low molecular substrates such as ions, nucleotides, and amino acids (Mori and Shimizu 2000). Undoubtedly, the cryopreservation can represent an intense stress for the cells, therefore, it is a possible explanation for the higher viability of vitrified-warmed intact oocytes compared to vitrifiedwarmed denuded oocytes in the present study.

Furthermore, in order to support oocyte maturation, cumulus cells should be in optimal conditions and should retain all their distinctive features such as proliferative activity, steroid production and FSH responsiveness. In all cell types, cryoinjury affects both cell structure and pathways of metabolism, in particular the antioxidant system (Tirelli et al., 2005). In addition, the previous studies with different species have shown that the surrounding cumulus cells have an important role in the oocyte meiotic maturation process (Soom et al., 2002; Abdel-Ghani et al.,
2012). Hence, the lower percentage of M-II oocytes in the denuded groups would be expected, and once again confirmed the significant functional role of cumulus cells in the promotion of nuclear maturation of oocytes.

Moreover, the cumulus cells are important for increasing the concentration of intracellular glutathione of oocytes (Abeydeera et al., 1998). The intracellular glutathione has an important role in protecting cells against oxidative stress, and was correlated with nuclear and cytoplasmic maturation (Abeydeera et al., 1998).

In conclusion, the results of the present study indicate that the contact of cumulus cells with canine oocytes improved the viability after vitrification, and enhanced the meiotic resumption of canine oocytes after in vitro maturation. The understanding and improving of vitrification and IVM of canine oocytes might be used as a background for further development of canine ARTs and understanding of reproductive physiology, because, the successful development and application of ARTs are dependent on basic reproductive biotechnologies particularly IVM.

\section{REFERENCES}

Abdel-Ghani, M.A.; Shimizu, T.; Asano, T. and Suzuki, H. (2012): In vitro maturation of canine oocytes co-cultured with bovine and canine granulosa cell monolayers. Theriogenology, 77: 347-355.

Abe, Y.; Lee, D.; Kim, K. and Suzuki, H. (2008): Vitrification of canine oocytes. J. Mamm. Ova. Res., 25: 32-36.

Abe, Y.; Asano, T.; Abdel-Ghani, M.A. and Suzuki, H. (2010): Vitrification of canine cumulusoocyte complexes in DAP213 with a cryotop holder. Reprod. Med. Biol., 9: 115-120.

Abe, Y.; Suwa, Y.; Asano, T.; Shirasuna, S.; AbdelGhani, M.A.; Oi, M.; Kobayashi, M.; Miyahara, K. and Suzuki, H. (2011): Cryopreservation of Canine Embryos. Biol, Reprod., 84: 363-368.

Abeydeera, L.R.; Wang, W.H.; Cantley, T.C.; Rieke, A. and Day, B.N. (1998): Co-culture with follicular shell pieces can enhance the developmental competence of pig oocytes after in vitro fertilization: relevance to intracellular glutathione. Biol. Reprod., 58: 213-218.

Bolamba, D.; Russ, K.D.; Harper, S.A.; Sandler, J.L. and Durrant, B.S. (2006): Effects of epidermal growth factor and hormones on granulosa expansion and nuclear maturation of dog oocytes in vitro. Theriogneology, 65: 10371047.

Concannon, P.W.; McCann, J.P. and Temple, M. (1989): Biology and endocrinology of 
ovulation, pregnancy and parturition in the dog. J. Reprod.Fertil. Suppl., 39: 3-25.

De los Reyes, M.; De Lange, J.; Miranda, J.P. and Claudio, B. (2005): Effect of human chorionic gonadotrophin supplementation during different culture periods on in vitro maturation of canine oocytes. Theriogenology, 64: 1-11.

England, G.C.W.; Verstegen, J.P. and Hewitt, D.A. (2001): Pregnancy following in vitro fertilization of canine oocytes. Vet. Rec., 148: 20-22.

Fujihira, T.; Kishida, R. and Fukui, Y. (2004): Developmental capacity of vitrified immature porcine oocytes following ICSI: effects of cytochalasin B and cryoprotectants. Cryobiology, 49: 286-290.

Gilula, E.M. and Beers, W.H. (1978): Cell-to-cell communication and ovulation: a study of the cumulus oocyte complexes. J. Cell. Biol., 78: 58-75.

Ishijima, T.; Kobayashi, Y.; Lee, D.S.; Ueta, Y.Y.; Matsui, M. and Lee, J.Y. (2006): Cryopreservation of canine ovaries by vetrification. J. Reprod. Dev., 52: 293-299.

Luvoni, G.C.; Modina, S. and Gandolfi, F. (2001): Influence of different stages of the oestrous cycle on cumulus-oocyte communications in canine oocytes: effects on the efficiency of in vitro maturation. J. Reprod. Fertil., 57: 410 414.

Mori, T.A. and Shimizu, H. (2000): Roles of gap junctional communication of cumulus cells in cytoplasmic maturation of porcine oocytes cultured in vitro. Biol. Reprod., 62: 913-919.

Motta, P.M.; Naguro, S.M. and Correr, S. (1994): Oocyte follicle cells association during development of human ovarian follicle. A study by high resolution scanning and transmission electron microscopy. Arch. Histol. Cytol., 57: 369-394.
Newton, H.; Fisher, J.; Arnold, J.R.; Pegg, D.E.; Faddy, M.J. and Gosden, R.G. (1998): Permeation of human ovarian tissue with cryoprotective agents in preparation for cryopreservation. Hum. Reprod., 13: 376-380.

Renton, J.P.; Boyd, J.S.; Eckersall, P.D.; Ferguson, J.M.; Harvey, M.J.A.; Mullaney, J. and Perry, B. (1991): Ovulation, fertilization and early embryonic development in the bitch (Canisfamiliaris). J. Reprod. Fertil., 93: 221231.

Songsasen, N.; Yu, I.; Gomez, M. and Leibo, S.P. (2003): Effects of meiosis-inhibiting agents and equine chorionic gonadotropin on nuclear maturation of canine oocytes. Mol. Reprod. Dev., 65: 435-445.

Soom, A.V.; Tanghe, S.; Pauw, I.D.; Maes, D. and Kruif, A.D. (2002): Function of the cumulus oophorus before and during mammalian fertilization. Reprod. Domest. Anim., 37: 144151.

Suzuki, H.; Ishijima, T.; Maruyama, S.; Ueta, Y.; Abe, $Y$. and Saitoh, H. (2008): Beneficial effect of desialylated erythropoietin administration on the frozen-thawed canine ovarian xenotransplantation. J. Assist. Reprod. Genet., 25: 571-575.

Tirelli, M.; Basini, G.; Grasselli, F. and Tamanini, C. (2005): Cryopreservation of pig granulosa cells: effects of FSH addition to freezing medium. Dom. Anim. Endocrinol., 28: 17-33.

Van den Broecke, R.; Liu, J.; Handyside, A.; Van der Elst, J.C.; Krausz, T. and Dhont, M. (2001): Follicular growth in fresh and cryopreserved human ovarian cortical grafts transplanted to immunodeficient mice. Eur. J. Obstet. Gynecol. Reprod. Biol., 97:193-201.

Whitingham, D.G. (1974): Embryos banks in the future of developmental genetics. Genetics, 78: 395-402.

\section{تأثير الخلايا الركامية علي تزجيج بويضات الكلاب باستخدام محلول DAP213}

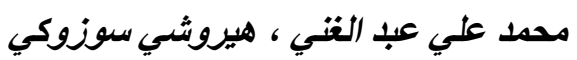

E-mail: mohammed_ali76@hotmail.com

تم في هذا البحث دراسة تأثثر الخلايا الركامية علي تزجيج بويضات الكلاب باستخدام محلول DAP213.

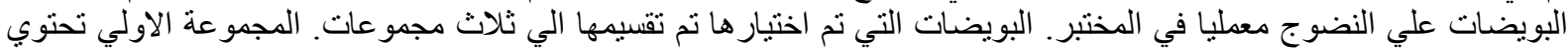

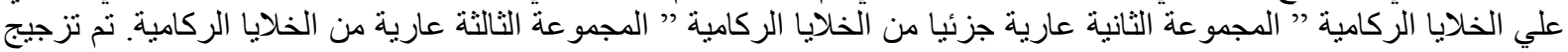

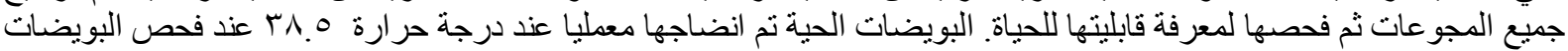

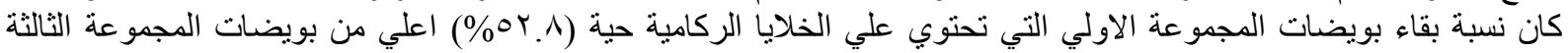

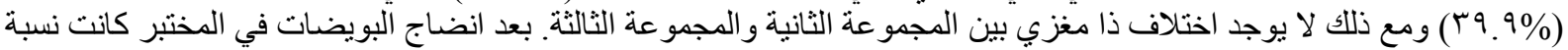

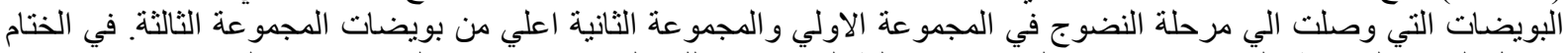

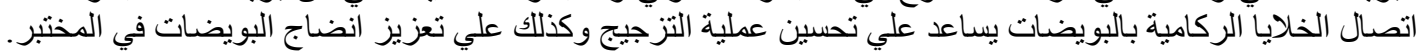

